\title{
Characterization of CONS Isolated from Clinical Samples of Paediatric Cases in a Tertiary Care Hospital
}

\author{
T.S. Kumudini ${ }^{1 *}$ and Shivakumar S. Solabannavar ${ }^{2}$ \\ Department of Microbiology, Vijayanagar Institute of Medical Sciences, \\ Cantonment area, Ballari-583104, Karnataka, India \\ *Corresponding author
}

\begin{tabular}{|l|}
\hline Ke y w o r d s \\
$\begin{array}{l}\text { S. epidermidis, } \\
\text { Linezolid and } \\
\text { Amikacin }\end{array}$ \\
\hline Article Info \\
\hline $\begin{array}{l}\text { Accepted: } \\
\text { 04 June } 2019 \\
\text { Available Online: } \\
\text { 10 July } 2019\end{array}$ \\
\hline
\end{tabular}

\section{Introduction}

Coagulase negative staphylococci (CoNS) were incriminated in life threatening blood stream nosocomial infection in critically ill newborn or patient receiving immunosuppressive therapy for malignant neoplasm, hematological malignancy and bone marrow transplant.3 The increased incidence of CoNS infections in neonates has occurred predominantly in low birth weight
Coagulase negative staphylococci (CoNS) were generally considered to be contaminants in the past having little clinical significance. Over the past two decades, these organisms have become recognized as important agents of human disease. S. epidermidis is the predominant agent in nosocomial infection, bacteremia, surgical wound and urinary tract infections. Their pathogenic potential is being increasingly understood and also causing problems to clinicians because of their drug resistance. Characterization of CoNS isolated from clinical samples of paediatric cases, their antibiogram and methicillin resistance. The study was conducted from December 2014 to August 2015. The organisms were identified and speciation was done by standard biochemical reactions. Antibiotic susceptibility testing was done by Kirby-Bauer disk diffusion method and following Clinical laboratory standards institute guidelines (2015). The maximum isolates were from female patients 21 $(55 \%)$ than male patients $17(45 \%)$. Most common age group affected was Neonate (1-28 days) (29\%) in both sex followed by Infant (29 days -12 months) in female (13\%) and in male (8\%). The majority of CoNS species isolated were S. epidermidis $19(50 \%)$, followed by S. haemolyticus 9 (24\%), S. xylosus 3 (8\%), S. lugdunensis 2 (5\%), S. hominis 2 (5\%), S. cohnii $2(5 \%)$ and S. saprophyticus $1(3 \%)$. S. epidermidis was the predominant species isolated. The most effective antibiotics were Linezolid and Amikacin. 
possibly implicated with the bacterial persistence and dissemination in the host tissue.6 Clinical studies, have indicated $S$. epidermidis, S. haemolyticus, S. warneri and $S$. hominis as the most prevalent CoNS in hospital infections.6,7

The majority of infections assumed to be caused by CoNS are a significant consequence of hospitalization.8 Nosocomial bacteraemia is most commonly caused by CoNS, so it is important to explore the sources of CoNS for prevention and management of infections. 9 This type of study was not conducted so far in this Institute, an attempt was made to isolate and speciate CoNS from various clinical samples with their antibiogram.

Characterzation of CoNS isolated from clinical samples of paediatric cases, their antibiogram and methicillin resistance.

\section{Materials and Methods}

This was an observational study and conducted at Department of Microbiology, S Nijalingappa Medical College and Hospital, Bagalkot from December 2014 to August 2015 after obtaining the Institutional Ethical Committee clearance. All clinical samples were collected under aseptic precautions and following standard clinical laboratory guidelines. The isolates were identified as CoNS by colony morphology, Gram stain, catalase test and coagulase test (slide and tube coagulase). Bacitracin (0.04 U) susceptibility was performed to exclude Micrococci and Stomatococcus species.8

The strains which were slide and tube coagulase negative were selected for further speciation. Speciation was done after reviewing the scheme of Kloos and Schleifer and Koneman, et al., 7,8,9 The various biochemical tests used for speciation are as follows:
Ornithine decarboxylase test, Phosphatase test, Urease test, Nitrate reduction test and Carbohydrate fermentation test (Mannose, Mannitol and Xylose).

The antibiotic sensitivity testing was performed on Mueller-Hinton agar by the Kirby-Bauer disc diffusion method, The antibiotics included $\operatorname{Amikacin}(\mathrm{AK})$ ), Amoxicillin-Clavulanate (AMC), Cotrimoxazole (COT), Ciprofloxacin (CIP), Doxycycline (DO), Erythromycin (E), Gentamicin (GEN), Linezolid (LZ) Norfloxacin (NX), Nitrofurantoin (NIT), Novobiocin (NV) and Cefoxitin10 (CX). Four to five colonies from 16 to 24 hours grown culture from an agar plate was suspended in peptone water. This is compared with 0.5 McFarland turbidity standards and inoculated onto Mueller Hinton Agar to get a confluent growth. Plates were incubated at $37 \mathrm{oC}$ for 18 to 24 hours. Zone of growth inhibition was measured.11

Detection of Methicillin resistance: Cefoxitin $(\mathrm{CX}-30 \mu \mathrm{g})$ was used to identify methicillin resistant coagulase negative Staphylococci (MR-CoNS) 10and Staphylococcus aureus ATCC 25923 was used as control strain. A 0.5 Mc Farland suspension of the isolate was made and lawn culture done on MHA plate. Plates were incubated at $30^{\circ} \mathrm{C}$ for $18 \mathrm{~h}$ and zone diameters were measured. An inhibition zone of $\geq 22 \mathrm{~mm}$ was considered as susceptible and $\leq 21 \mathrm{~mm}$ resistant for cefoxitin. The results of the test are interpreted as sensitive and resistant as per CLSI Guidelines (2015). 10

\section{Results and Discussion}

The maximum isolates were from female patients $21(55 \%)$ than male patients 17 (45\%). Most common age group affected was Neonate (1-28 days) (29\%) in both sex followed by Infant (29 days -12 months) in 
female (13\%) and in male (8\%). The majority of CoNS were isolated from blood $32(84 \%)$, followed by urine $5(13 \%)$ and ascitic fluid 1 (3\%). The majority of CoNS species isolated were S. epidermidis 19 (50\%), followed by $S$. haemolyticus 9 (24\%), S. xylosus 3 (8\%), S. lugdunensis 2 (5\%), S. hominis 2 (5\%), S. cohnii $2(5 \%)$ and S. saprophyticus 1(3\%). 23 (61\%) were methicillin resistant and 15 (39\%) were methicillin sensitive. All the strains of CoNS were sensitive to Linezolid (100\%), Amikacin (79\%) and Doxycycline (76\%).However they were resistant to Amoxycillin-Clavulanic acid 25 (66\%), Cotrimoxazole 24 (63\%) and Ciprofloxacin 17 $(45 \%)$.

CoNS are the most frequently reported pathogen in blood stream infection, especially patient with indwelling or implanted foreign polymer bodies. CoNS species apparently changing the status from non-pathogens to opportunistic pathogens. ${ }^{12}$ Simplicity and speed are very important in certain circumstances, e.g., for the identification of CoNS isolates from normally sterile body sites such as blood cultures, in which these isolates are the most common cause of bacteremia, as well as the most common blood culture contaminants. Repeated CoNS isolates from patients with invasive diseases should be identified and allow a comparison of the strains. On the other hand, species identification is a prerequisite for epidemiological studies.13 CoNS were responsible $11 \%(35 / 320)$ of bacteremia cases in our study. The CoNS positive bacteremia found maximum $28(80 \%)$ in age group 0-14 years in our study, co-relate with study by Parashar ${ }^{1}$. The CoNS species S. epidermidis was most frequent isolate $15(43 \%)$; followed by S. haemolyticus 10(29\%) and S. xylosus $3(9 \%)$ (Table 1-5).

Table.1 Showing Age wise and Sex wise distribution of CoNS (n=38)

\begin{tabular}{|l|c|c|}
\hline Age Groups & Male & Female \\
\hline Neonate (1-28 days) & 11 & 11 \\
\hline Infant (29 days-12 months) & 3 & 5 \\
\hline Toddler (1-3 years) & 1 & 0 \\
\hline Pre-school (3-5 years) & 1 & 0 \\
\hline School (6-10 years) & 1 & 2 \\
\hline Adolescent (11-14 years) & 0 & 3 \\
\hline Total & 17 & 21 \\
\hline
\end{tabular}

Table.2 Showing distribution of CoNS individual sample wise $(n=38)$

\begin{tabular}{|l|c|c|}
\hline Samples & Number & Percentage \\
\hline Blood & 32 & 84 \\
\hline Urine & 5 & 13 \\
\hline Ascitic fluid & 1 & 3 \\
\hline Total & 38 & 100 \\
\hline
\end{tabular}


Table.3 Different species of CoNS from various clinical samples $(n=38)$

\begin{tabular}{|l|c|c|}
\hline Species of CoNS & No. & $\%$ \\
\hline S. epidermidis & 19 & 50 \\
\hline S. haemolyticus & 9 & 24 \\
\hline S. xylosus & 3 & 8 \\
\hline S. lugdunensis & 2 & 5 \\
\hline S. hominis & 2 & 5 \\
\hline S. cohnii & 2 & 5 \\
\hline S. saprophyticus & 1 & 3 \\
\hline Total & 38 & 100 \\
\hline
\end{tabular}

Table.4 Showing resistance to Methicillin $(n=38)$

\begin{tabular}{|c|c|c|c|}
\hline \multicolumn{2}{|c|}{ Methicillin Sensitive } & \multicolumn{2}{c|}{ Methicillin Resistant } \\
\hline No. & $\%$ & No. & $\%$ \\
\hline 15 & 39 & 23 & 61 \\
\hline
\end{tabular}

Table.5 Showing Antibiogram of CoNS ( $n=38)$

\begin{tabular}{|l|c|c|c|c|}
\hline \multirow{2}{*}{ Antibiotic } & \multicolumn{2}{|c|}{ Sensitive } & \multicolumn{2}{c|}{ Resistant } \\
\cline { 2 - 5 } & No. & $\%$ & No. & $\%$ \\
\hline Amikacin & 30 & 79 & 8 & 66 \\
\hline Amoxicillin- & 13 & 34 & 25 & \\
\hline Clavulanate & & & & 63 \\
\hline Ciprofloxacin & 21 & 55 & 17 & 45 \\
\hline Doxycycline & 29 & 76 & 9 & 24 \\
\hline Erythromycin & 22 & 58 & 16 & 42 \\
\hline Gentamicin & 24 & 63 & 14 & 37 \\
\hline Linezolid & 38 & 100 & 0 & 0 \\
\hline *Norfloxacin & 3 & 60 & 2 & 40 \\
\hline *Nitrofurantoin & 3 & 60 & 2 & 40 \\
\hline
\end{tabular}

* For urinary isolates $(\mathrm{n}=5)$ 
The CoNS isolates in other studies, 35\% Sardar et al., ${ }^{14}, 32 \%$ Kavita et al., ${ }^{15}, 23 \%$ according to Jayanthi et al., ${ }^{16}, 22 \%$ Nagasugha et al., ${ }^{12}$, 14\% Golia et al., ${ }^{17}$ and our study $11 \%$. In our study, the common species were $S$. epidermidis and $S$. haemolyticus (43\% \& 29\%) respectively. Similarly in other studies by Nagasudha et al., ${ }^{12}\left(59 \%\right.$ \& 15\%), Jayanthi et al., ${ }^{16}$ (56\% \& $30 \%)$, Golia et al., ${ }^{17}(46 \%$ \& 20\%) and Sardar et al., ${ }^{14}$ (43\% \& 13\%).

Moreover the conventional identification methods are accurate and employ a large battery of biochemical reactions, which often give variable results and all the tests are generally not available in most of the routine diagnostic laboratories. The commercial identification methods including automated systems are not economical to use for all CoNS isolates.18 In our study resistant to methicillin was $63 \%$ similar to other studies by Aher et al., ${ }^{19}-78 \%$, Nagasuda et al., ${ }^{12}$ $66 \%$, Golia et al., ${ }^{17}-66 \%$ and Sardar et al., ${ }^{14}$ $-52 \%$. Methicillin resistant CoNS isolate, $S$. epidermidis $43 \%$ and S. haemolyticus $29 \%$. In the present study higher number of isolates was sensitive to linezolid $100 \%$, amikacin and doxycycline $77 \%$, gentamicin $63 \%$, erythromycin $60 \%$ and ciprofloxacin $54 \%$. The antibiogram of our study is similar to other studies, Aher et al., ${ }^{19}$, Kavita et al., ${ }^{15}$, Golia et al., ${ }^{17}$, Jayanthi et al., ${ }^{16}$, Nagasudha et al., 12, and Sardar et al., 14. Methicillin resistant CoNS (MR-CoNS) most notably $S$. epidermidis, $S$. haemolyticus, $S$. hominis are major MR-CoNS and main colonizers of the anterior nares and human skin. Methicillin resistant staphylococcal strains have acquired and integrated into their genome, the staphylococcal cassette chromosome mec (SCCmec),which carries the methicillin resistance (mecA) gene and other antibiotic resistance determinants. 20 The methicillin resistant organisms grow more slowly and prefer lower temperatures and more hypertonic environment, which necessitates the use of special procedures to enhance detection in susceptibility tests.21 Accuracy and promptness in the detection of methicillin resistance are of key importance in ensuring correct antibiotic treatment in infected patients and control of methicillin resistant staphylococci in the hospital environment. 22

CoNS are one of the most common infectious agent responsible for blood stream infection, especially in neonates with low birth weight or prematurity. Therefore suggest that CoNS strain should not discard as contaminants and should be identified up to species level with their antibiogram to decrease mortality and morbidity. It is important to monitor antibiotic consumption and resistance trends of staphylococci, especially with infection control measures to prevent emergence and spread of multi-resistant bacteria within the hospital environment.23Further studies are needed with well characterized standardized strains for the development of simple, inexpensive, accurate and more reliable schemes for characterization of clinically significant CoNS.

\section{References}

1. Parashar S. Coagulase negative staphylococci; a cause of nosocomial blood stream infection. Int $\mathrm{J}$ of scie Res 2014; 3(6): 277-78.

2. Seetha KS, Santosh PK, Shivananda PG. Study of coagulase negative staphylococci isolated from blood and CSF cultures. Indian J Pathol Microbiol 2000; 43(1):41-45.

3. Keim LS, Torres-Filho SR, Vollú Silva P, Teixeira LA. Prevalence, aetiology and antibiotic resistance profiles of coagulase negative staphylococci isolated in a teaching Hospital. Brazilian J Microbiol 2011; 42: 248-55.

4. Kloos WE, Schleifer KH. Simplified 
scheme for routine identification of human Staphylococcus species. J Clin Microbiol 1975; 1(1):82-9.

5. Hajera M, Mustafa M, Sreenivasa RC, Naidu NV, Kumar KV, Jayasimha RD. Prevalence and antibiotic susceptibility pattern of methicillin resistant staphylococci from a tertiary care Hospital in Hyderbad. Int $\mathbf{J}$ plant, animal \& Envi Sci 2014; 4(2): 65-9.

6. Woods GL, Hall GS, Rutherford I, Pratt KJ, Knapp CC. Detection of methicillin resistant Staphylococcus epidermidis. J Clin Microbiol 1986; 24(3):349-52.

7. Washington WC, Allen SD, Janda WM, Koneman EW, Procop GW, Schreckenberger PC. Koneman's Color Atlas and Textbook of Diagnostic Microbiology. $6^{\text {th }}$ ed. Philadelphia; Lippincott Company JB: 2006.

8. Holt JG, Kreig NR, Sneath PHA, Staley JT, Williams ST. Bergey's Manual of determinative bacteriology. $\quad 9^{\text {th }}$ ed. Baltimore; Lippincott Williams and Wilkins: 1994.

9. Forbes BA, Sahm DF, Weissfeld AS, Bailey and Scott's Diagnostic Microbiology. $13^{\text {th }}$ ed. Missouri: Mosby Elsevier: 2013.

10. CLSI: Performance Standards for antimicrobial susceptibility testing; Twenty- Third Informational Supplement. In CLSI documentM100S23 Wayne, PA; Clinical and Laboratory Standards Institute: 2015.

11. Collee JG, Marmion BP, Fraser AG, Simmons A. Mackie and McCartney Practical Medical Microbiology. $14^{\text {th }}$ ed. Edinburgh; Churchill Livingstone: 1996.

12. Nagasudharani J, Vidyarani SU, Suneetha N, Kasturi T, Ramana BV, Kailasanadha Reddy B. Speciation of coagulase negative staphylococci isolated from clinical samples with special reference to their antibiogram. Int J Pharma Res \& Bio Sci 2015; 4(1): 429-38.

13. De Pauli AN, Predari SC, Chazarreta CD, Santoianni JE. Five-Test simple scheme for species level identification of clinically significant coagulase negative Staphylococci. J Clin Microbiol 2003; 41:1219-24.

14. Sardar SA, Singh M, Basireddy S, Ali $\mathrm{S}$, Kabra V. Coagulase negative staphylococci among clinical isolates in a tertiary care centre. Int J Pharma Bio Sci 2015; 6(1): 229-36.

15. Kavitha Y, Shaik KM. Speciation and antibiogram of clinically significant coagulase negative staphylococci. Int $\mathbf{J}$ of Health Sci \& Res 2014; 4(12): 15761.

16. Jayanthi RS, Jomy J. Phenotypic characterization of clinically significant coagulase negative staphylococci and their susceptibility pattern in a tertiary care Hospital. Int J Curr Microbiol App Sci 2015; 4(4): 647-52.

17. Golia S, Telsang DB, Asha S, Kamath B, Tiwari D. Speciation of clinically significant coagulase negative staphylococci and their antibiotic resistant patterns in a tertiary care Hospital. Int J Res Med Sci 2015; 3(5): 1242-46.

18. Goyal R, Singh NP, Kumar A, Kaur I, Singh M, Sunita N, et al., Simple and economical method for speciation and resistotyping of clinically significant coagulase negative staphylococci. Indian J Med Microbiol 2006; 24:2014.

19. Aher CS. The isolation pattern, species distribution and antibiotic susceptibility profile of coagulase negative staphylococci: emerging opportunistic pathogens. Int $\mathbf{J}$ of Biomed \& Adv Res 2014; 5(1):23-5. 
20. Murugesan S, Perumal N, Mahalingam SP, Dilliappan S, Krishnan P. Analysis of antibiotic resistance genes and its associated SCCmec types among nasal carriage of methicillin resistant coagulase negative staphylococci from community settings, Chennai, Southern India. J of Clin Dignostic Res 2015; 9(8):1-5.

21. Woods GL, Hall GS, Rutherford I, Pratt KJ, Knapp CC. Detection of methicillin resistant Staphylococcus epidermidis. J Clin Microbiol 1986;
24(3):349-52.

22. Jain A, Agarwal A, Verma RK. Cefoxitin disc diffusion test for detection of meticillin resistant staphylococci. J Med Microbiol 2008; 57:957-61.

23. Koksal F YH, Samasti M. Antibiotic resistance patterns of coagulase negative Staphylococcus strains isolated from blood cultures of septicemic patients in Turkey. Microbiol Res 2007; 164(4):404-10.

\section{How to cite this article:}

Kumudini, T.S. and Shivakumar S. Solabannavar. 2019. Characterization of Cons Isolated from Clinical Samples of Paediatric Cases in a Tertiary Care Hospital. Int.J.Curr.Microbiol.App.Sci. 8(07): 67-73. doi: https://doi.org/10.20546/ijcmas.2019.807.009 